\title{
Size-Selective Predation Mortality and Growth Rates of 0-group Bivalves Macoma balthica Modeled from Size Distributions
}

\author{
Henrike Andresen (Corresponding author) \\ Department Marine Ecology, Royal Netherlands Institute for Sea Research \\ PO Box 59, 1790 AB Den Burg, Texel, The Netherlands \\ Present address:
}

Department Marine Ecology, National Institute of Water and Atmospheric Research

Gate 10 Silverdale Road, Hillcrest, Hamilton 3216, USA

Tel: 64-21-773-824 E-mail: henrikea@gmx.de

\begin{abstract}
Rob Dekker
Department Marine Ecology, Royal Netherlands Institute for Sea Research

PO Box 59, 1790 AB Den Burg, Texel, the Netherlands

E-mail: Rob.Dekker@nioz.nl
\end{abstract}

Jaap van der Meer

Department Marine Ecology, Royal Netherlands Institute for Sea Research

PO Box 59, 1790 AB Den Burg, Texel, the Netherlands

$\&$

Department of Theoretical Biology, Free University Amsterdam

de Boelelaan 1085, 1081 HV Amsterdam, the Netherlands

E-mail: Jaap.van.der.Meer@nioz.nl

Received: October 20, 2014 Accepted: November 21, 2014 Published: January 1, 2015

doi:10.5296/ast.v3i1.6812 URL: http://dx.doi.org/10.5296/ast.v3i1.6812 


\begin{abstract}
We simulated growth and size-selective predation mortality of juvenile Wadden Sea bivalves, predicted size distributions of prey Macoma balthica shaped by their predators Crangon crangon (Brown shrimp), and compared these predictions with observations in the field. Under the assumption that all mortality is caused by shrimp, size-selective predation could explain bivalve size structure in several cases with quite realistic and consistent prey choice functions. In about half of the 14 studied time periods, bivalve size structures could not be reproduced by selective shrimp predation, but unselective mortality never led to a reliable fit of the field data. We conclude that size-dependent abundance changes are the rule in the early life of these bivalves. Various size-dependent processes such as migrations could affect local abundances. The results strongly support that a major determinant of young M. balthica abundance and size distribution of the survivors is predation by shrimp.
\end{abstract}

Keywords: Body size, Wadden Sea, Recruitment, Population structure, Shrimp, Post-settlement processes 


\section{Introduction}

Individual growth in aquatic and marine taxa, such as mollusks and fish, is commonly of the indeterminate type (Kooijman, 2000; Kozlowski, 1996). Environment and individual energetics add variability to this life history trait. As a consequence, interacting species may co-occur over a large range of possible body size ratios during their lives. Body size is crucial to predator-prey interactions (Brooks \& Dodson, 1965). Prey capture and handling success depend on the sizes of both predator and prey (Claessen, Van Oss, de Roos \& Persson, 2002). As predation mortality is affected by body size, predators can change the size structure of their prey population (Rice, Crowder \& Rose, 1993; Sparevik \& Leonardson, 1999).

Predation by crustaceans is considered to play an important role in the recruitment success of bivalves in the European Wadden Sea (Beukema \& Dekker, 2005; Hiddink, Marijnissen, Troost \& Wolff, 2002; Strasser, 2002). Relative timing of peak crustacean and bivalve settler abundances varies between years (Philippart et al., 2003; Strasser \& Günther, 2001), so that different predator and prey body sizes may encounter over time each year. We investigate the interaction of young infaunal bivalves Macoma balthica (Baltic tellin) and their most abundant epifaunal predators Crangon crangon (Brown shrimp). Size-selectivity of their predator-prey relationship has been demonstrated in lab experiments (Andresen \& van der Meer, 2010; Hiddink et al., 2002) and field experiments (Andresen, Dorresteijn \& van der Meer, 2013). Differences in bivalve size distributions between years at the time of recruitment in August have been observed (Strasser, Hertlein \& Reise, 2001), and are possibly due to such selective predation. Yet, studies relating predator and prey structure analytically are rather limited when benthic invertebrates are considered.

Individual-based models are useful to evaluate whether effects of individual variability need to be considered in understanding year class variation, or whether an approach based on averages is already sufficient (Rice et al., 1993). Studies conducted in relation to fisheries research (e.g. Paradis \& Pepin, 2001) and also in systems with invertebrate prey (e.g. Sparevik \& Leonardson, 1999) show the necessity of including size structure in studies of early mortality.

Field observations of $M$. balthica and C. crangon size distributions over time in the Wadden Sea were the starting point for the present study. With simulations we analyzed what combinations of bivalve growth rates and size selection by the predators would be able to bring about the observed changes in bivalve size distributions. The outcomes of a model version assuming that all mortality was caused by size-selective predation by shrimp are compared to a version that assumes unselective mortality. Size-related mortality can also occur through processes other than predation (Green, Jones, Boudreau, Moore \& Westman, 2004). If the estimated prey preference by shrimp turns out to be very variable between study periods or has to be unrealistic to achieve a good fit, then other processes must dominate over predation in determining bivalve size distribution and mortality. The aim is to determine how common and dominant size-selective predation by shrimp is in shaping the size distribution of the surviving young M. balthica. 


\section{Material and Methods}

\subsection{Data}

2.1.1 Study site and temporal sampling design

Bivalves and crustaceans were sampled at a site within the Balgzand tidal flats in the westernmost part of the Dutch Wadden Sea. Tidal range at Balgzand is $-80 \mathrm{~cm}$ to $+60 \mathrm{~cm}$ respective to mean sea level, the sampling site lies in the upper range of the middle intertidal zone at about $10 \mathrm{~cm}$ above mean sea level. The habitat can be characterized as uniform bare fine sand. Sampling took place in the years 1994 to 1998, at several occasions between May and November, the crucial phase determining Macoma balthica recruitment. See Tables 1 and 2 for the exact sampling dates each year for bivalves and crustaceans, respectively. Within these five years of field data, 14 periods occurred in which bivalve density decreased and shrimp observations were available.

Table 1. Bivalve sampling dates, number of individuals and total sampling area per date

\begin{tabular}{|c|c|c|c|c|c|c|c|c|c|}
\hline & & 1994 & 1995 & 1996 & & & 1997 & 1998 & \\
\hline \multirow[t]{3}{*}{ May } & Date & & $22^{\text {nd }}$ & & & & $21^{\mathrm{st}}$ & $13^{\text {th }}$ & $28^{\text {th }}$ \\
\hline & $n$ & & 87 & & & & 391 & 42 & 11 \\
\hline & Area $\left(\mathrm{cm}^{2}\right)$ & & 807 & & & & 672 & 403 & 403 \\
\hline \multirow[t]{3}{*}{ Jun } & Date & $23^{\mathrm{rd}}$ & $27^{\text {th }}$ & $13^{\text {th }}$ & & & $18^{\text {th }}$ & & \\
\hline & $n$ & 63 & 27 & 142 & & & 125 & & \\
\hline & Area $\left(\mathrm{cm}^{2}\right)$ & 644 & 807 & 1340 & & & 403 & & \\
\hline \multirow[t]{3}{*}{ Jul } & Date & $19^{\text {th }}$ & $24^{\text {th }}$ & $3^{\text {rd }}$ & $16^{\text {th }}$ & $29^{\text {th (1) }}$ & $16^{\text {th }}$ & & \\
\hline & $n$ & 57 & 19 & 234 & 54 & 63 & 143 & & \\
\hline & Area $\left(\mathrm{cm}^{2}\right)$ & 1076 & 807 & 2687 & 2687 & 672 & 538 & & \\
\hline \multirow[t]{3}{*}{ Aug } & Date & & $22^{\text {nd }}$ & & & & $28^{\text {th }}$ & & \\
\hline & $n$ & & 57 & & & & 77 & & \\
\hline & Area $\left(\mathrm{cm}^{2}\right)$ & & 5400 & & & & 538 & & \\
\hline \multirow[t]{3}{*}{ Sep } & Date & $19^{\text {th }}$ & $21^{\mathrm{st}}$ & $10^{\text {th }}$ & & & $15^{\text {th }}$ & & \\
\hline & $n$ & 41 & 36 & 24 & & & 72 & & \\
\hline & Area $\left(\mathrm{cm}^{2}\right)$ & 1076 & 2700 & 540 & & & 672 & & \\
\hline \multirow[t]{3}{*}{ Oct } & Date & & & $9^{\text {th (1) }}$ & & & & & \\
\hline & $n$ & & & 30 & & & & & \\
\hline & Area $\left(\mathrm{cm}^{2}\right)$ & & & 403 & & & & & \\
\hline \multirow[t]{3}{*}{ Nov } & Date & & & $26^{\text {th }}$ & & & & & \\
\hline & $n$ & & & 305 & & & & & \\
\hline & Area $\left(\mathrm{cm}^{2}\right)$ & & & 10200 & & & & & \\
\hline
\end{tabular}

Note: ${ }^{(1)}$ No density decrease towards this sampling event. 


\subsubsection{Bivalve sampling}

Bivalve samples were taken haphazardly within a plot of $100 \mathrm{~m}^{2}$ during low tide. Sampling area was adapted to decreasing bivalve densities by changing the number of samples taken at a sampling event (three to ten), as well as the number of cores pooled per sample (two to ten), and corer area (27 or $90 \mathrm{~cm}^{2}$ ). Table 1 gives details of the total sampling area per date, and the number of $M$. balthica individuals found. Sampling depth was $8 \mathrm{~cm}$ in 1994 and $5 \mathrm{~cm}$ in later years. Samples were sieved in the lab over $300 \mu \mathrm{m}$ mesh screen, only in 1998 a $150 \mu \mathrm{m}$ sieve was used. At some occasions additional larger samples were taken, to a depth of $15 \mathrm{~cm}$ and sieved over larger mesh $(1 \mathrm{~mm})$, to get a better chance of catching the largest of the young bivalves, which occur in lower densities. The abundance estimates of the bivalves that are retained on a $1 \mathrm{~mm}$ sieve come from both the standard and the large samples; this gave smoother size-frequency distributions. The abundance they would have had in the area of the standard samples was calculated, because scaling the number of individuals up to a larger area would lead to a seemingly high accuracy of the subsequent statistical test. Bivalves were sorted live or preserved in $4 \%$ formalin in buffered seawater. Shell lengths were measured with $100 \mu \mathrm{m}$ accuracy.

Table 2. Shrimp sampling dates and densities

\begin{tabular}{|c|c|c|c|c|c|c|}
\hline & & 1994 & 1995 & 1996 & 1997 & 1998 \\
\hline \multirow[t]{2}{*}{ May } & Date & & & & & $13^{\text {th }}$ \\
\hline & Density $/ \mathrm{m}^{2}$ & & & & & 54 \\
\hline \multirow[t]{2}{*}{ Jun } & Date & $30^{\text {th }}$ & $12^{\text {th }}$ & $26^{\text {th }}$ & $5^{\text {th }}$ & \\
\hline & Density $/ \mathrm{m}^{2}$ & 25 & 56 & 72 & 51 & \\
\hline \multirow[t]{2}{*}{ Jul } & Date & & $12^{\text {th }}$ & $16^{\text {th }}$ & $2^{\text {nd }}$ and $31^{\text {st }}$ & \\
\hline & Density $/ \mathrm{m}^{2}$ & & 31 & 78 & 111 and 38 & \\
\hline \multirow[t]{2}{*}{ Aug } & Date & $23^{\mathrm{rd}}$ & $9^{\text {th }}$ & $22^{\text {nd }}$ & $25^{\text {th }}$ & \\
\hline & Density $/ \mathrm{m}^{2}$ & 36 & 117 & 3 & 77 & \\
\hline \multirow[t]{2}{*}{ Sep } & Date & & $5^{\text {th }}$ & & & \\
\hline & Density $/ \mathrm{m}^{2}$ & & 59 & & & \\
\hline \multirow[t]{2}{*}{ Oct } & Date & & & $9^{\text {th }}$ & & \\
\hline & Density/m² & & & 36 & & \\
\hline \multirow[t]{2}{*}{ Nov } & Date & & & & & \\
\hline & Density $/ \mathrm{m}^{2}$ & & & & & \\
\hline
\end{tabular}

Note: Total sampling area per date was always $0.36 \mathrm{~m}^{2}$.

\subsubsection{Crustacean sampling}

Shrimp were sampled during low tide in four $10 \mathrm{~m}$ long transects just outside the $10 \times 10 \mathrm{~m}^{2}$ bivalve plot. Each time, 40 cores of each $90 \mathrm{~cm}^{2}$ area were taken, adding up to a total sampling area of $0.36 \mathrm{~m}^{2}$. Sampling depth was ca. $5 \mathrm{~cm}$, and samples were sieved in the field 
over $1 \mathrm{~mm}$ mesh screen. Crangon crangon were sorted out live in the lab and their length measured from telson to scaphocerite to the nearest $\mathrm{mm}$.

\subsection{Model}

Simulations were carried out to find out which combination of bivalve growth rate and prey choice by shrimp could best predict the observed change in M. balthica size distribution. Random encounters between the observed predators and the observed initial bivalve prey were simulated, and a preference curve by the predator decided on the outcome of the encounter - consumption by the shrimp or survival of the bivalve. Mortality events and growth periods were alternated, so they were spread evenly over the time period, until the prey numbers were reduced to the abundance observed at the end of a time period. The resulting size distributions were compared to the field distributions by Kolmogorov-Smirnov tests (Zar, 1999). The steps of the procedure are explained in more detail below and are illustrated in Fig. 1.

Exponential growth was assumed, as appropriate for post-larval bivalves (Urban, 2002), with a single mean instantaneous growth rate parameter. On top of this average rate, for each period and for each individual a small randomly chosen and normally distributed growth variation was added with a standard deviation of 0.15 times the mean growth rate. Prior analyses showed that such growth variation gives a natural looking size distribution and that the results are quite robust to the amount of growth rate variation. Growth created much smaller size increments in the simulations than the measurement accuracy in the observed data had been. For this reason, bivalve lengths were drawn from a uniform distribution within $0.1 \mathrm{~mm}$ of the measurements.

The predator-prey encounter rate was scaled to predator body size. The searching rate as well as the width of the searched area scales with predator length, thus the encounter rate scales with squared predator length (Kooijman, 2000). The body size of the small bivalve prey was considered negligible for scaling the probability of predator-prey encounters. For all predator sizes, selection takes place on the basis of predator/prey length ratio. For a given predator size, it has been suggested that the chance that a prey encounter results in a kill should be a dome-shaped function of prey body size. (Lundvall, Svanback, Persson \& Bystrom, 1999). We used the normal curve as the shape of the preference curve. The preference curve gives the probability that an encounter results in prey death as a function of relative prey length. The maximum value is obtained at the preferred relative prey length. The standard deviation was chosen to be $1 / 3$ of the preferred relative prey length. If the predators were not able to reduce the prey to the target abundance through their prey choice after 5000 encounters, the simulation was terminated. For the case of unselective mortality, the bivalves to be removed from the cohort were drawn randomly. After a bivalve was removed from the cohort, the remaining bivalves grow. 

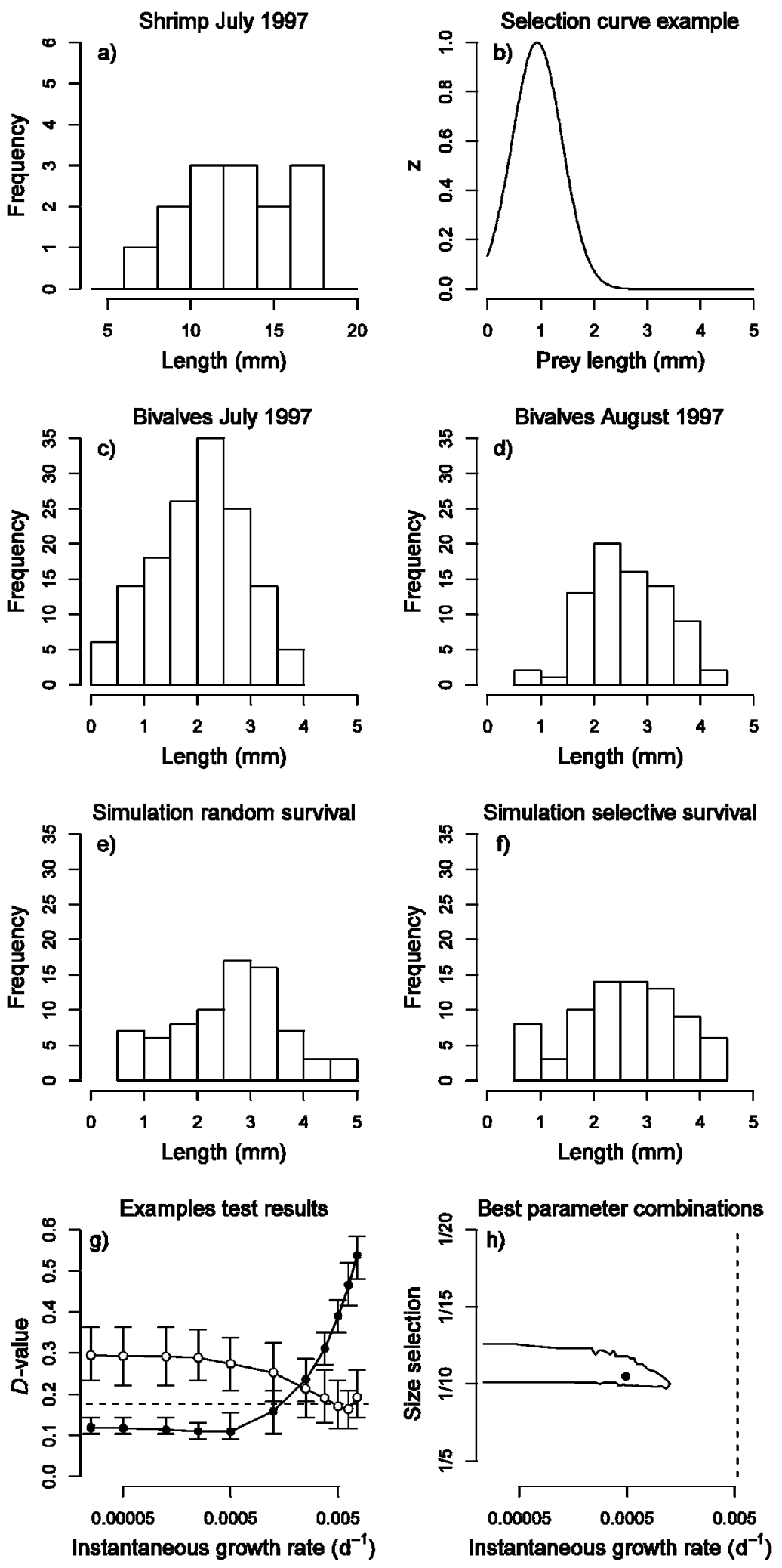

Figure 1. Illustration of the modeling procedure

Notes: a) Observed size distribution of shrimp, example from July 1997. b) Example of a prey selection curve, for a $14 \mathrm{~mm}$ long shrimp that chooses prey $1 / 15$ of the predator length. c) Observed size distribution of Macoma 
balthica in July 1997. d) Observed size distribution of $M$. balthica the next month. e) Example of a simulated size distribution of $M$. balthica, using the July data as a starting point for growing and random mortality. f) Example of a simulated size distribution of M. balthica, using the July data as a starting point for growing and selective predation. g) Resulting $D$-statistic of the Kolmogorov-Smirnov tests comparing simulated with observed data, set out against the tested growth rates. As examples, the black dots are the averages of each 500 $D$-values obtained using a prey preference for $1 / 11$ of the predator length, the white dots were obtained with size-independent mortality. The error bars represent $95 \%$ confidence intervals. The horizontal dashed line marks the critical $D$-value. Values below it indicate that the compared size distributions are not significantly different. h) Contour plot of the best parameter combinations for the example period. The black dot represents the combination of growth rate and prey preference that leads to the lowest average $D$-value when simulated and observed data are compared. For all parameter combinations within the contour, at least $95 \%$ of the resulting $D$-values are below the critical $D$-value. The vertical dashed line marks the best fitting growth rate for the case of unselective mortality; however, no growth rate led to sufficiently low $D$-values in combination with random mortality.

When the bivalves were reduced to the final abundance, the simulated size distribution resulting from the respective parameter combination of growth rate and preferred relative prey length was compared with the observed field size distribution by a Kolmogorov-Smirnov test (KS-test). The aim was to find the combination of the two parameters that do not lead to a significant difference in size distribution between observed and simulated. For every parameter combination, the simulation with alternating mortality and growth and the KS-test in the end was repeated 500 times. The parameter combinations for which the $97.5 \%$-quantile of the $D$-values remained under the critical $D$-value for the particular $n$ are concluded to be able to explain the observed bivalve size distribution.

Recall that the bivalve sampling area in the field was adjusted to bivalve density. This implies that the difference in the counts of individuals sampled between dates does not directly resemble the change in density. Therefore, the number of animals at the beginning of a time period was changed, while keeping the body size composition, such that the decrease in $n$ until the end of the time period corresponds to the density decrease. The $n$ at the end must not be changed, as this changes the apparent power of the KS-test. Further, when the smallest individuals in the end of a time period were smaller than the smallest in the beginning, they were removed, as this is probably due to later settlement into the area.

\section{Results}

In seven out of the 14 investigated periods, simulations with size-selective predation by the observed shrimp were able to reproduce the observed size distributions of Macoma balthica (Fig. 2). In the other cases, neither selective predation by the present shrimp nor random mortality led to a resemblance with the observed bivalve size distributions. That means size-dependent abundance changes must have taken place, but not, or not only, caused by shrimp predation. These periods were mainly early in the season, and in the whole year of 1996. 

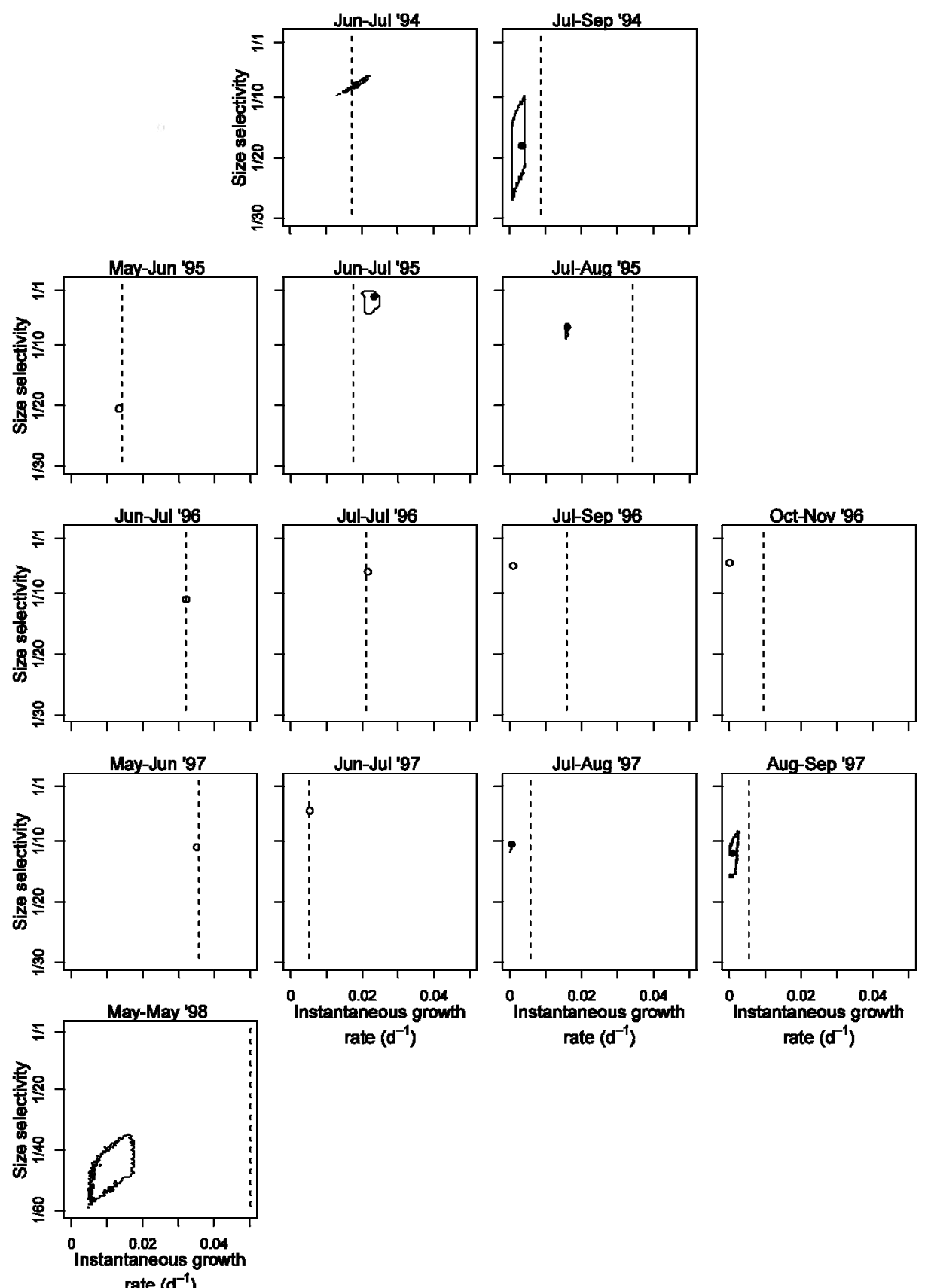

rate $\left(\mathrm{d}^{-1}\right)$

rate $\left(d^{-1}\right)$

rate $\left(\mathrm{d}^{-1}\right)$

Figure 2. Estimates of prey selection by shrimp and bivalve daily instantaneous growth rate

Notes: A size selection of e.g. 1/10 means that a shrimp selects bivalves of a tenth of its own length. The black dot indicates the best fitting combination of prey preference and growth rate from simulations with size-selective predation. The solid contour contains all parameter combinations that resulted in prey size distributions similar to the observed size distribution in at least $95 \%$ of the simulations. When there is no contour drawn, no parameter combination led to a fit with the field data, and the dot is filled white. The dashed vertical line indicates the best fitting growth rate from simulations with size-independent, random mortality. No growth rate value led to a fit with the field data in combination with unselective mortality, so no confidence region is drawn around the dashed line. 
In the cases where size-selective shrimp predation produced bivalve size distributions similar to the field observations, the selected prey size was often around a tenth of the predator size. One time, the estimated choice was half of the predator size, and in one case the estimated selected size was much smaller, 1/50 of the predator's size. The corresponding estimates of the bivalves' instantaneous growth rates range from $0.00025^{-\mathrm{d}}$ to $0.025^{-\mathrm{d}}$ between all investigated time periods that got a fit with the data. Turning to the prey point of view, the results also point to which sizes of the bivalves were most affected. In most of the cases where predation could explain the bivalves' size distribution, estimated growth rates were lower than those assuming unselective mortality. This means that of the available bivalves, the smallest ones have been fed on, as ignoring predation gives the illusion of faster growth. Only in the first investigated time period, growth rate estimates were similar with or without size-selective predation.

\section{Discussion}

For many of the investigated periods of the five summers studied, simulations supported predation by shrimp as the driving force of size-selective mortality. Usually bivalves at the lower end of the present size spectrum were affected. With about a tenth of the predator's size, these smaller sizes often represented the maximum of what shrimp could take (Hiddink et al., 2002; Keus, 1986, as cited in van der Veer, Feller, Weber \& Witte, 1998). This points to a potential for the bivalves to outgrow this predator. The choice for prey half the predator's size found in one instance (June to July 1995) is unrealistic. Also the preference for extremely small prey, relative to the predator and also compared to the available prey size range (May 1998), is in conflict with feeding on the center of the available size distribution at the maximum of the predator's ability (June to July 1994). Of the estimated values of the resulting growth rates, the higher ones are similar to growth rates obtained by individual marking in situ (Andresen et al., 2013).

Are there methodological limitations that could have had an effect on the results? The observed size structures of the bivalves can often not be explained by shrimp predation alone, but they can never be explained by simple bivalve growth in combination with unselective mortality, not even when the predator abundance was very low (July to September 1996, Fig. 2 , Table 2). One might question the adequacy of the very simple growth model that has been assumed. Yet, assuming constant instantaneous growth is realistic for the early period, when growth is indeed almost exponential. In individual marking experiments (Andresen et al., 2013) we found that the lines of Ford-Walford plots were not converging, and that instantaneous growth rates did not change with bivalve size. It should be mentioned for completeness that out of curiosity simulations for growth with random mortality were also done with von Bertalanffy growth, in which the ultimate length was fixed. Even then, only in one out of 14 cases did unselective mortality lead to a matching size distribution at the end of the period. Thus, size-dependent processes are the rule in the early months of a bivalve cohort. In the periods where the estimated preference values deviate strongly from the other estimates (June to July 1995 and within May 1998), size-selective loss probably occurred through another process, but the attempt to link this to the present shrimp sizes led to the exceptional estimates. There could be additional predators, such as infaunal polychaetes, but 
also dissolution mortality (Green et al., 2004), competitive ability and starvation resistance or susceptibility to diseases could depend on size. One well known process in the early benthic life of young Macoma balthica is their secondary migration (Beukema, 1993; Hiddink \& Wolff, 2002), which is also size-specific (Armonies, 1992). Sometimes additional settlement was identified in the data by the appearance of smaller individuals, which were removed from the analysis, but not all additional settlers may have been able to be identified that way, and that could give a distorted image.

Shape and width of the prey preference curve were chosen indirectly and the position judged on the basis of literature (Landvall et al., 1999, Hiddink et al., 2002). Shape and width of the preference curve could affect the size of the confidence region around the parameter estimates. The estimates of the preferred prey size were often at or just above the limit of the experimentally determined ability of shrimp (Hiddink et al., 2002). An underestimation of the number of big shrimp through sampling during low tide could have led to an overestimation of the preferred prey size by the observed shrimp. At high tide bigger shrimp enter the tidal flats for foraging (Janssen \& Kuipers, 1980). This could also lead to an underestimation of the bivalve growth rates, because lower growth fits better with the lack of bigger bivalve individuals that may have been consumed by the undocumented bigger shrimp.

The simulations were done knowingly under the far-reaching assumption that all mortality is due to shrimp predation. Considering that a lot of other processes can potentially affect bivalve size distributions, it is remarkable that parameter estimates were consistent and realistic in so many cases. Even more so since the investigated time spans were short, while a comparable study in a piscivore system showed that size-selective mortality is more easily predicted in longer periods (Paradis \& Pepin, 2001). Hence it is plausible that size-selective shrimp predation is an influential process, which not only has a strong impact on size distributions, but also must make a major contribution to total pre-recruit mortality. Selective loss is dominated by the predator with the greatest impact on the survivors (Paradis \& Pepin, 2001).

The data originate from a single sampling site, while bivalve and crustacean abundances and sizes vary in space. However, the chosen site lies in the relevant intertidal area where the highest number of encounters between predators and prey is expected due to their zonations. The focus of this study was the identification of processes, but the results may not represent the population quantitatively.

Concerning further research, an approach that tackles the problem from the other side would use detailed information on prey choice to quantify predation rates. Prey choice experiments until now (Hiddink et al., 2002; Keus, 1986, as cited in van der Veer et al., 1998) have established the upper limit of the predation window of shrimp feeding on M. balthica. The required experiments are not simple, because prey choice may depend on relative densities and alternative prey. Further, our results show that estimating growth rates from size distributions alone is inaccurate and individual marking methods (Andresen et al., 2013) are needed. Strong selectivity implies that there are important differences among individuals. In 
the future it will be interesting to not only investigate the consequences of variability among individuals of a bivalve cohort, but also the sources of variability.

\section{Acknowledgement}

This study was financially supported by the Netherlands Organization for Scientific Research (NWO) and Netherlands-Bremen Oceanography II (NEBROC).

\section{References}

Andresen, H., \& van der Meer, J. (2010). Brown shrimp (Crangon crangon, L.) functional response to density of different sized juvenile bivalves Macoma balthica (L.). Journal of Experimental Marine Biology and Ecology, 390, 31-38. http://dx.doi.org/10.1016/j.jembe.2010.04.027

Andresen, H., Dorresteijn, I., \& van der Meer, J. (2013). Growth and size-dependent loss of newly settled bivalves in two distant regions of the Wadden Sea. Marine Ecology Progress Series, 472, 141-154. http://dx.doi.org/10.3354/meps10011

Armonies, W. (1992). Migratory rhythms of drifting juvenile molluscs in tidal waters of the Wadden Sea. Marine Ecology-Progress Series, 83, 197-206. http://dx.doi.org/10.3354/meps083197

Beukema, J. J. (1993). Successive changes in distribution patterns as an adaptive strategy in the bivalve Macoma balthica (L) in the Wadden Sea. Helgoländer Meeresuntersuchungen, 47, 287-304. http://dx.doi.org/10.1007/bf02367170

Beukema, J. J., \& Dekker, R. (2005). Decline of recruitment success in cockles and other bivalves in the Wadden Sea: possible role of climate change, predation on postlarvae and $\begin{array}{lllll}\text { fisheries. } \quad \text { Marine } \quad \text { Ecology-Progress } & \text { Series, } & \text { 287, }\end{array}$ http://dx.doi.org/10.3354/meps287149

Brooks, J. L., \& Dodson, S. I. (1965). Predation, body size and composition of plankton. Science, 150, 28-35. http://dx.doi.org/10.1126/science.150.3692.28

Claessen, D., Van Oss, C., de Roos, A. M., \& Persson, L. (2002). The impact of size-dependent predation on population dynamics and individual life history. Ecology, 83, 1660-1675. http://dx.doi.org/10.2307/3071986

Green, M. A., Jones, M. E., Boudreau, C. L., Moore, R. L., \& Westman, B. A. (2004). Dissolution mortality of juvenile bivalves in coastal marine deposits. Limnology and Oceanography, 49, 727-734. http://dx.doi.org/10.4319/1o.2004.49.3.0727

Hiddink, J. G., \& Wolff, W. J. (2002). Changes in distribution and decrease in numbers during migration of the bivalve Macoma balthica. Marine Ecology-Progress Series, 233, 117-130. http://dx.doi.org/10.3354/meps233117

Hiddink, J. G., Marijnissen, S. A. E., Troost, K., \& Wolff, W. J. (2002). Predation on 0-group and older year classes of the bivalve Macoma balthica: interaction of size selection and 
intertidal distribution of epibenthic predators. Journal of Experimental Marine Biology and Ecology, 269, 223-248. http://dx.doi.org/10.1016/s0022-0981(02)00002-3

Janssen, G. M., \& Kuipers, B. R. (1980). On tidal migration in the shrimp Crangon crangon. Netherlands Journal of Sea Research, 14, 339-348. http://dx.doi.org/10.1016/0077-7579(80)90007-1

Kooijman, S. A. L. M. (2000). Dynamic Energy and Mass Budgets in Biological Systems. Cambridge: Cambridge University Press.

Kozlowski, J. (1996). Optimal allocation of resources explains interspecific life-history patterns in animals with indeterminate growth. Proceedings Of The Royal Society Of London Series B-Biological Sciences, 263, 559-566. http://dx.doi.org/10.1098/rspb.1996.0084

Lundvall, D., Svanback, R., Persson, L., \& Bystrom, P. (1999). Size-dependent predation in piscivores: interactions between predator foraging and prey avoidance abilities. Canadian Journal of Fisheries and Aquatic Sciences, 56, 1285-1292. http://dx.doi.org/10.1139/cjfas-56-7-1285

Paradis, A. R. \& Pepin, P. (2001). Modelling changes in the length-frequency distributions of fish larvae using field estimates of predator abundance and size distributions. Fisheries Oceanography, 10, 217-234. http://dx.doi.org/10.1046/j.1365-2419.2001.00167.x

Philippart, C. J. M., van Aken, H. M., Beukema, J. J., Bos, O. G., Cadee, G. C., \& Dekker, R. (2003). Climate-related changes in recruitment of the bivalve Macoma balthica. Limnology and Oceanography, 48, 2171-2185. http://dx.doi.org/10.4319/lo.2003.48.6.2171

Rice, J. A., Crowder, L. B., \& Rose, K. A. (1993). Interactions between size-structured predator and prey populations - Experimental test and model comparison. Transactions of The American Fisheries Society, 122, 481-491. http://dx.doi.org/10.1577/1548-8659(1993)122<0481:ibsspa $>2.3 . c o ; 2$

Sparrevik, E., \& Leonardsson, K. (1999). Direct and indirect effects of predation by Saduria entomon (Isopoda) on the size-structure of Monoporeia affinis (Amphipoda). Oecologia, 120, 77-86. http://dx.doi.org/10.1007/s004420050835

Strasser, M. (2002). Reduced epibenthic predation on intertidal bivalves after a severe winter in the European Wadden Sea. Marine Ecology-Progress Series, 241, 113-123. http://dx.doi.org/10.3354/meps241113

Strasser, M., \& Günther, C. P. (2001). Larval supply of predator and prey: temporal mismatch between crabs and bivalves after a severe winter in the Wadden Sea. Journal of Sea Research, 46, 57-67. http://dx.doi.org/10.1016/S1385-1101(01)00063-6

Strasser, M., Hertlein, A., \& Reise, K. (2001). Differential recruitment of bivalve species in the northern Wadden Sea after the severe winter of 1995/96 and of subsequent milder winters. Helgoland Marine Research, 55, 182-189. http://dx.doi.org/10.1007/s101520100080 


\section{Macrothink}

Aquatic Science and Technology

ISSN 2168-9148 2015, Vol. 3, No. 1

Urban, H. J. (2002). Modeling growth of different developmental stages in bivalves. Marine Ecology-Progress Series, 238, 109-114. http://dx.doi.org/10.3354/meps238109

van der Veer, H. W., Feller, R. J., Weber, A., \& Witte, J. I. J. (1998). Importance of predation by crustaceans upon bivalve spat in the intertidal zone of the Dutch Wadden Sea as revealed by immunological assays of gut contents. Journal of Experimental Marine Biology And Ecology, 231, 139-157. http://dx.doi.org/10.1016/s0022-0981(98)00090-2

Zar, J. H. (1996). Biostatistical Analysis ( $3^{\text {rd }}$ ed.). New Jersey: Prentice Hall.

\section{Copyright Disclaimer}

Copyright for this article is retained by the author(s), with first publication rights granted to the journal.

This is an open-access article distributed under the terms and conditions of the Creative Commons Attribution license (http://creativecommons.org/licenses/by/3.0/). 